\title{
Dlgap1 negatively regulates browning of white fat cells through effects on cell proliferation and apoptosis
}

Ju Zhang ${ }^{1,2}$, Jie Yang ${ }^{1,2}$, Nan Yang ${ }^{1,2}$, Jianfei Ma ${ }^{1,2}$, Datong Lu ${ }^{1,2}$, Yanhua Dong ${ }^{1,2}$, Hao Liang ${ }^{1,2}$, Dongjun Liu ${ }^{1,2}$ and Ming Cang ${ }^{1,2^{*}}$

\begin{abstract}
Background: Obesity is a metabolic imbalance characterized by excessive deposition of white fat. The browning of white fat can effectively treat obesity and related diseases. Although Dlgap1 (Discs, Large (Drosophila) HomologAssociated Protein 1) is suspected to have an effect on this process, no empirical evidence is available.

Methods: To understand the role of Dlgap1, we cultured white and brown fat cells, then performed overexpression and knockout experiments.

Results: We found that Dlgap1 overexpression in brown adipocytes inhibits brown-fat-related gene expression, promotes white-fat-related genes, while also increasing brown-adipocyte proliferation and apoptosis. However, the gene overexpression has no effect on brown adipocyte maturation. Knocking out Dlgap1 in white fat cells promotes the expression and inhibition of brown-fat-related and white-fat-related genes, respectively. Additionally, the knockout inhibits white fat cell proliferation and apoptosis, while also promoting their maturation.
\end{abstract}

Conclusions: Dlgap 1 negatively regulates the browning of white adipocytes by influencing cell proliferation and apoptosis.

Keywords: Dlgap1, Proliferation, Apoptosis, Brown fat, White fat

\section{Background}

Obesity has become a public health crisis because it is a risk factor for cardiovascular disease, type 2 diabetes, hypertension, stroke, and many cancers $[1,2]$. Because chronic energy imbalance is the primary cause of most weight gain, nonsurgical therapy must reduce energy intake or increase energy expenditure, or both [3].

Adipocytes (fat cells) form three metabolically distinct categories: white, beige, and brown [4-6]. White adipose tissue (WAT) stores excess energy in the form of triglycerides, while brown adipose tissue (BAT) transfers chemical

\footnotetext{
* Correspondence: cangming@imu.edu.cn

1State Key Laboratory of Reproductive Regulation \& Breeding of Grassland Livestock, Inner Mongolia University, Hohhot 010070, China

${ }^{2}$ College of Life Science, Inner Mongolia University, Hohhot 010070, China
}

energy into heat as a defense against hypothermia and obesity [7]. Recent findings using a novel radiodiagnosis technique revealed unexpectedly high BAT activity in adult humans $[6,8-10]$. These studies have also identified complex cell differentiation processes leading to the appearance of active brown adipocytes. Data on rodents suggest that brown adipocytes clustered in defined anatomical BAT depots arise from mesenchymal precursor cells common to the myogenic cell lineage [11]. Brown adipocytes of this origin are now called "classical" or "developmentally programmed" [12]. However, brown adipocytes also appear after thermogenic stimuli at anatomical sites corresponding to WAT, in a process called "browning" [12]. Initial studies suggest that browning of WAT can effectively treat obesity

C C The Author(s). 2020 Open Access This article is licensed under a Creative Commons Attribution 4.0 International License, which permits use, sharing, adaptation, distribution and reproduction in any medium or format, as long as you give appropriate credit to the original author(s) and the source, provide a link to the Creative Commons licence, and indicate if changes were made. The images or other third party material in this article are included in the article's Creative Commons licence, unless indicated otherwise in a credit line to the material. If material is not included in the article's Creative Commons licence and your intended use is not permitted by statutory regulation or exceeds the permitted use, you will need to obtain permission directly from the copyright holder. To view a copy of this licence, visit http://creativecommons.org/licenses/by/4.0/ The Creative Commons Public Domain Dedication waiver (http://creativecommons.org/publicdomain/zero/1.0/) applies to the data made available in this article, unless otherwise stated in a credit line to the data. 
and related diseases [13], but more data are needed to clarify this link.

Existing studies have focused on transcription factors [13-16], secreted proteins [17-19], small RNA [20-23], and other variables [24] that affect browning. In this study, we aimed to identify key genes that regulate browning, laying a solid foundation for studying obesity. The Dlgap1 protein product is also known as synapseassociated protein 90/postsynaptic density 95 (PSD95)associated protein 1 (SAPAP1)s [25], DLG and PSD95associated protein (DAP-1) [26], and guanylate-kinaseassociated protein (GKAP) [27]. Dlgap1 is involved in type 2 diabetes [28], the development and maintenance of normal brain function [29], and interaction with the motor protein dynein [30]. This article verifies that Dlgap1 expression is significantly different in white and brown fat and negatively regulates the browning of white adipocytes by influencing cell proliferation and apoptosis.

\section{Methods}

\section{Cell isolation and culture}

Inguinal WAT and interscapular BAT were washed thoroughly with sterile phosphate-buffered saline (PBS) to remove blood cells. The tissues were then minced and shaken in $0.2 \%$ collagenase type II at $37^{\circ} \mathrm{C}$ for $1 \mathrm{~h}$. The cells were centrifuged at $1500 \mathrm{~g}$ for $5 \mathrm{~min}$ to remove the supernatant, and then plated on a collagen-coated Petri dish for culturing at $37^{\circ} \mathrm{C}$ in $5 \% \mathrm{CO}_{2}$. The medium was Dulbecco's modified Eagle's medium/nutrient mixture F12 (DMEM/F12), 10\% fetal bovine serum (FBS), $100 \mathrm{U}$ penicillin, and $100 \mathrm{mg} / \mathrm{mL}$ streptomycin.

\section{Construction of Dlgap1 overexpression plasmid}

C57BL/6 mouse Dlgap1 cDNA was cloned from brain tissue. The primers were as follows: $5^{\prime}$-ACAGGATCGAGG AAGCCAGA-3' (forward) and 5'-CGAAGCTCGG TGGAGAAGAT-3' (reverse). The PCR product and the pIRES2-EGFP vector were digested with SalI and SmaI restriction endonucleases. Next, the Dlgap1 fragment was ligated into the pIRES2-EGFP vector.

\section{Construction of Dlgap1 knockout plasmid using CRISPR/Cas9} The Dlgap1 coding region was obtained and submitted to http://crispr.dbcls.jp/ and http://crispr.mit.edu/ to design four sgRNAs that targeted the first $200 \mathrm{bp}$ of the Dlgap1 coding sequence. Targeted sequences were synthesized and annealed to form doublestranded DNA that served as templates for evaluating sgRNAs. These templates were ligated to the skeleton vector pCas-Guide-EF1a-GFP via T4 DNA ligase to form the CRISPR/Cas9 knockout vector.

\section{Liposome-mediated transfection}

Adipocytes at $60-70 \%$ confluence were transfected using Lipofectamine LTX with PLUS reagent (Invitrogen, Karlsruhe, Germany). Lipofectamine and plasmids were separately diluted in Opti-MEM (Gibco, Munich, Germany). The two solutions were mixed in a 1:1 ratio, incubated for $5 \mathrm{~min}$ at $20-25^{\circ} \mathrm{C}$, and added to the cells.

\section{RT-qPCR}

Total RNA was extracted using RNAiso Plus (TaKaRa Bio, Shiga, Japan) following the manufacturer's protocol, and then treated with gDNA Eraser to eliminate genomic DNA. Next, cDNA was synthesized using Prime Script RT Enzyme Mix I (TaKaRa Bio). Real-time PCR conditions were based on the manufacturer's protocol in the TaKaRa Real-Time PCR Kit. A 7500 Real-Time PCR system was used for the reactions. Relative expression was determined using the comparative Ct $\left(2^{-\Delta \Delta C t}\right)$ method $(n=3)$. The primers are listed in Table S1.

\section{Western blotting}

Western blotting was performed as described previously [31] Overexpression and knockout cells were washed with PBS and lysed in ice-cold lysis buffer with a protease inhibitor cocktail (Mammalian Protein Extraction Kit, KW Biotechnology, Beijing, China). Protein concentrations were measured using the BCA Protein Assay Kit (23,225, Thermo, USA). Proteins $(10 \mathrm{mg})$ were separated with SDS polyacrylamide gel electrophoresis (SDS-PAGE), transferred onto polyvinylidene difluoride (PVDF) membranes, and incubated with primary antibodies overnight at $4{ }^{\circ} \mathrm{C}$. Signals were then visualized using the Thermo Scientific Pierce ECL western blotting substrate and the Tanon 5200 (Tanon, Shanghai, China) detection system.

The primary antibodies used were anti-DLGAP1 (bs12138R, Bioss), anti-UCP1 (Ab10983, Abcam), antiPRDM16 (63,976, ABclonal), anti-FNDC5 (Ab174833, Abcam), anti-ACC (21923-1-AP, Proteintech), antiPPARY (16643-1-AP, Proteintech), anti-ASC1 (Ab70627, Abcam), anti-PSAT1 (10501-1-AP, Proteintech), antiFABP4 (15872-1-AP, Proteintech), anti-PGC1 $\alpha$ (206581-AP, Proteintech), anti-FASN (10624-2-AP, Proteintech), anti-LEPTIN (Ab16227, Abcam), anti-GAPDH (Ab9485, Abcam) and anti- $\alpha$-tubulin (11224-1-AP, Proteintech). The secondary antibody was HRP-conjugated AffiniPure Goat Anti-Rabbit lgG (H+L) (SA00001-2, Proteintech).

\section{Immunofluorescence staining}

Cells were fixed with $4 \%$ paraformaldehyde, permeabilized with $0.25 \%$ Triton X-100, and stained with primary antibodies (see "Western blotting") overnight at $4{ }^{\circ} \mathrm{C}$. After two PBS washes, the cells were incubated with fluorescein isothiocyanate-labeled secondary antibodies (ab7080, 
Abcam) at room temperature for $1 \mathrm{~h}$. For the negative controls, the primary antibodies were replaced with PBS.

\section{5-Ethynyl-2'-deoxyuridine (EdU) assays}

This cellular proliferation assay involved fluorescence detection using EdU (RuiBo, Guangzhou, China), a thymidine analog that can be incorporated into newly synthesized DNA during cell proliferation. At $24 \mathrm{~h}$ post-transfection, adipocytes were incubated with $\mathrm{EdU}(50 \mu \mathrm{M})$ for $2 \mathrm{~h}$, fixed in $4 \%$ paraformaldehyde, permeabilized with $0.5 \%$ Triton $\mathrm{X}-100$, and labeled with Apollo ${ }^{\circ}$ fluorescent dye (RuiBo, Guangzhou, China) following the manufacturer's protocol. The EdU-positive cells were imaged with a confocal microscope (Nikon, Tokyo, Japan) to calculate their percentage.

\section{Adipogenic differentiation}

Cells at $80 \%$ confluence were cultured in induction medium (90\% DMEM/F12, 10\% FBS, $1 \mu \mathrm{M}$ dexamethasone, $1 \mu \mathrm{M} 1$-methyl-3-isobutylxanthine, $1 \mu \mathrm{M}$ insulin). Two days later, the medium was replaced with differentiation medium (90\% DMEM/F12, 10\% FBS, $1 \mu \mathrm{M}$ insulin) for another $2 \mathrm{~d}$. Controls were cultured in DMEM/ F12 with 10\% FBS. The cells were then fixed in 4\% paraformaldehyde for $15 \mathrm{~min}$ and stained with Oil-Red working solution for $30 \mathrm{~min}$. The stained cells were washed with $60 \%$ isopropanol and imaged. To measure absorbance $(550 \mathrm{~nm})$, isopropyl alcohol was added to dissolved the lipid droplets, and the mixture was placed in a microplate reader (Thermo Scientific ${ }^{\mathrm{m}}$ ).

\section{Apoptosis measurements}

Cells were digested with trypsin to assay apoptosis using the Cell Cycle and Apoptosis Analysis Kit (7Sea Biotech, Shanghai, China). The treated cells were viewed immediately at room temperature with an inverted fluorescence microscope (Nikon TE2000-U, Japan). Flow cytometry was performed using a BD FACScan system (BD Biosciences, Franklin Lakes, NJ, USA). The data were analyzed with FlowJo 7.6 software.

\section{Statistical analysis}

All data are shown as means \pm SD from three individual experiments. Between-group differences were determined with the two-tailed Student's t-test in GraphPad Prism 5 (GraphPad Software, La Jolla, CA, USA). Significance was set at $P<0.05$.

\section{Results}

\section{Isolation and identification of white and brown} adipocytes in C57BL/6 mice

White adipose tissue accumulates under the skin, mainly in the groin, presenting as an even, milky white color from the large amount of oil present. Brown adipose tissue is located between the shoulder blades and gets its reddish-brown coloration from numerous blood cells (Fig. 1a). After $10 \mathrm{~d}$ of culturing experimentally isolated adipocytes, we observed that the white fat cells were $80 \%$ confluent, while the brown fat cells were only $40 \%$ confluent, indicating a significantly slower growth rate of the latter. Fluorescence phase contrast imaging revealed that the white and brown adipocytes did not differ significantly in morphology (Fig. 1a).

We then analyzed RNA expression of marker genes in white and brown adipocytes using RT-qPCR. We found that the white-fat marker genes Asc1, Leptin, and Adipoq [32] were 3.03, 9.33, and 207.03 times higher in white adipocytes than in brown adipocytes, respectively. Additionally, the brown-fat marker genes Cidea, Fndc5, Pgc1 $\alpha$, Prdm16, and Ucp1 [10, 33] were expressed at lower levels in white adipocytes, being $0.0034,0.229,0.060,0.582$, and 0.0095 times the expression in brown adipocytes, respectively (Fig. 1b). Western blots confirmed the RT-qPCR results (Fig. 1c). Furthermore, immunofluorescence revealed that Ucp1 expression was nearly absent in white adipocytes, but obvious in brown adipocytes. Leptin was expressed in white adipocytes, but not in brown adipocytes (Fig. 1d). Oil red $\mathrm{O}$ staining showed that the differentiation of white and brown fat cells occurred at $8 \mathrm{~d}$ (Fig. 1e). Cell morphology differed visibly between the two adipocyte types. A mature white adipocyte presented with a large lipid droplet in the center of the cell (single foam fat), whereas a mature brown adipocyte contained many small lipid droplets.

\section{Overexpression of Dlgap1 reduces browning-specific gene expression}

Using mouse brain tissue as a template, we amplified the coding sequence of Dlgap1 and generated the pRIRES2-EGFP-Dlgap1 overexpression vector (Fig. 2a). The constructed vector was identified through enzyme digestion and electrophoresis (Fig. 2a). The vector's successful construction was further verified through sequencing.

At $48 \mathrm{~h}$ post-transfection of the overexpression vector into brown adipocytes, we analyzed RNA and protein expression. Our RT-qPCR results showed that Dlgap1 overexpression in brown adipocytes increased Acc, Asc1, Leptin and Scd expression, while decreasing Cidea, Fabp4, Pgc1a, Prdm16, Ppary and Ucp1expression (Fig. 2c). Western blot assays (Fig. 2d) showed that Dlgap1 overexpression in brown fat cells dramatically reduced browning-specific proteins (FABP4, PGC1 $\alpha$, PPAR $\gamma$, PRDM16 and UCP1), while increasing white-fatrelated proteins (ACC, PAST1, LEPTIN, and FASN). Immunofluorescence analysis of LEPTIN and UCP1 was consistent with the western blot data (Fig. 2b). 


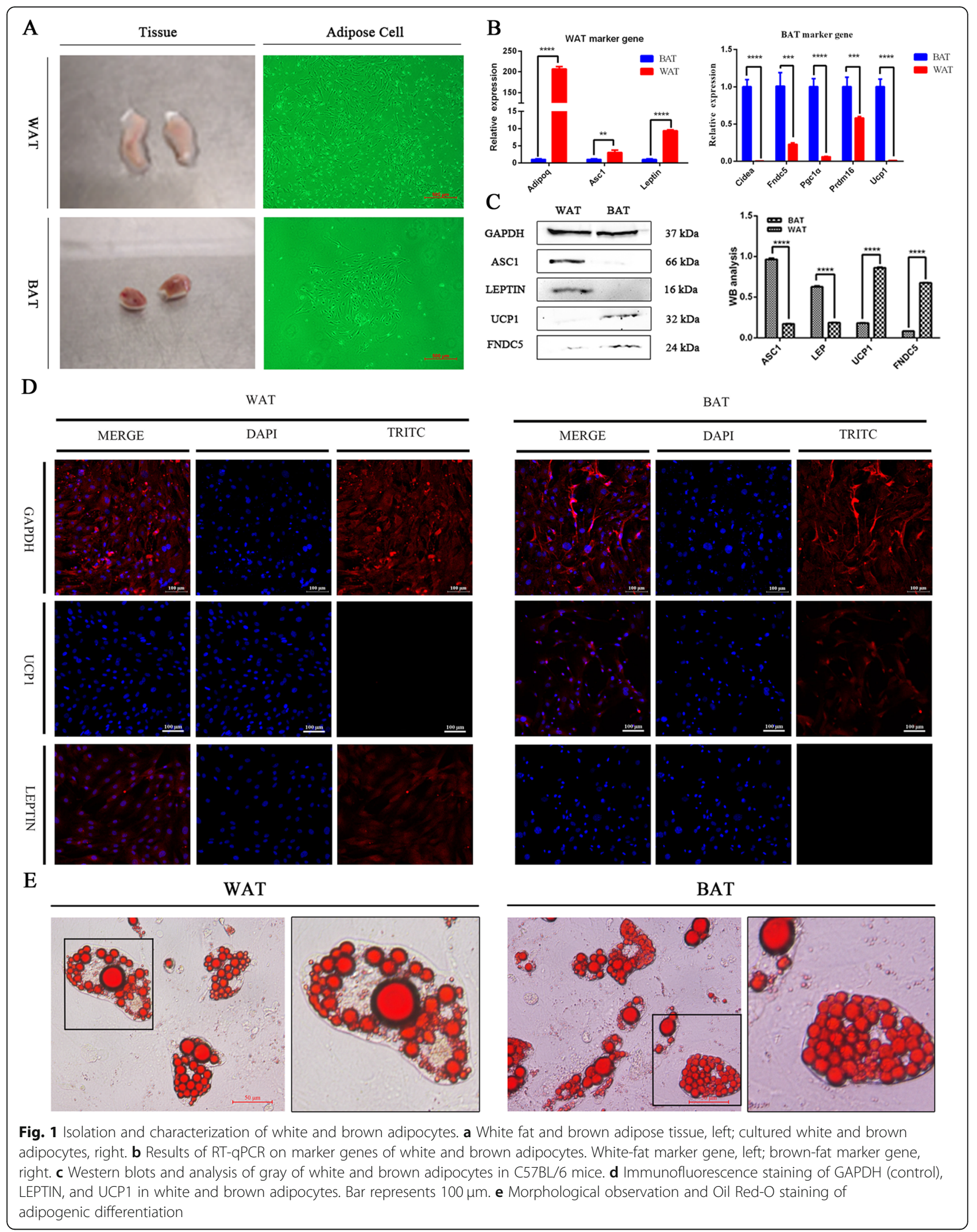




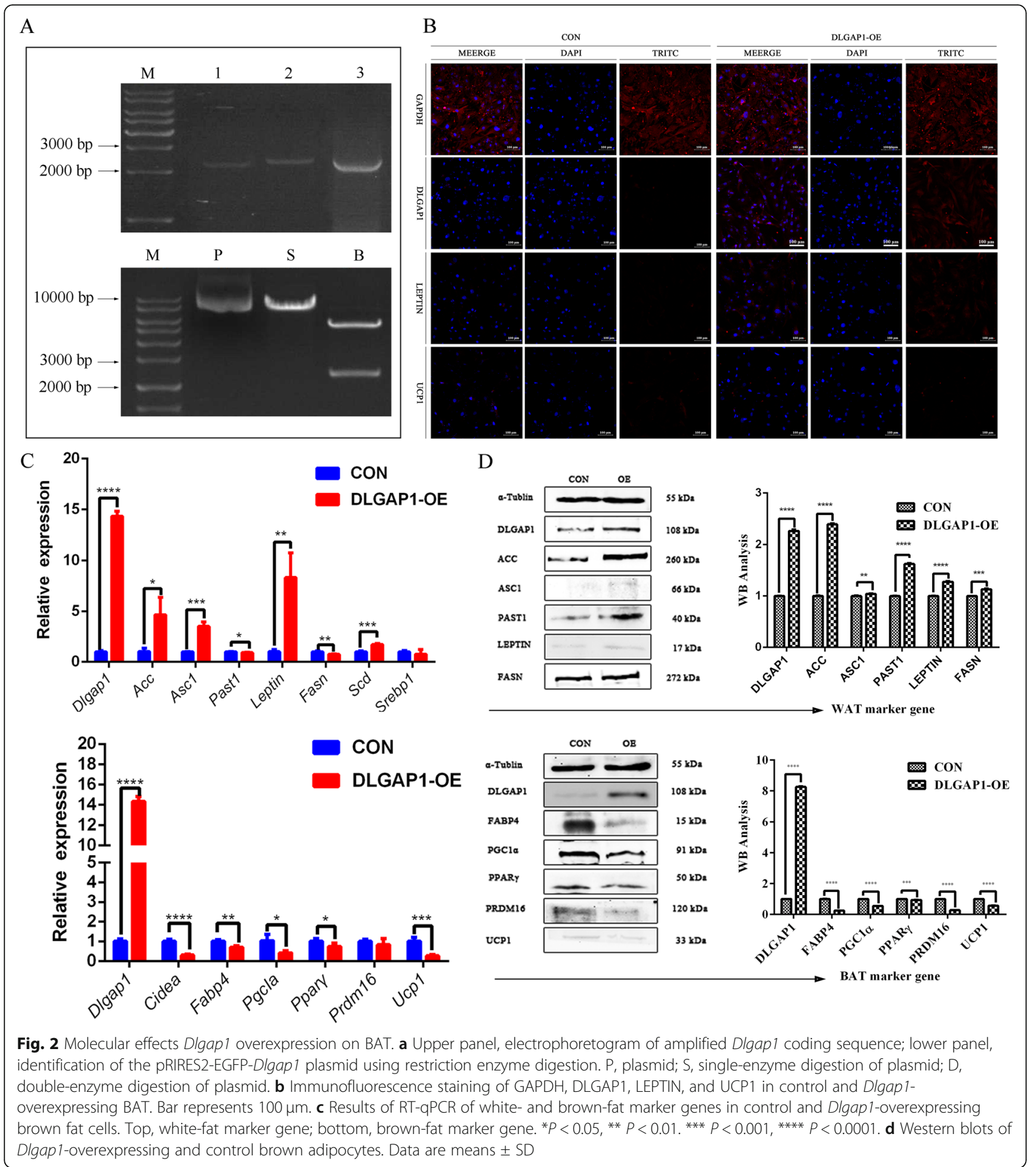

\section{Overexpression of Dlgap1 inhibits brown adipocyte} formation

The results of EdU proliferation assays revealed that Dlgap1 overexpression increased brown adipocyte formation. Fluorescent cells were counted under a confocal laser microscope (Fig. 3a). Oil red $\mathrm{O}$ staining showed that Dlgap1 overexpression did not significantly influence adipogenic differentiation (Fig. 3b). Flow cytometry revealed that Dlgap1 overexpression inhibited brown adipocyte apoptosis. As a result, the experimental overexpression group had 4.6 times more than the control group did (Apoptosis rate $=\mathrm{Q} 2+$ Q3) (Fig. 3c). These results indicate that Dlgap1 is required for the full activation of a gene program favoring brown adipocytes. 

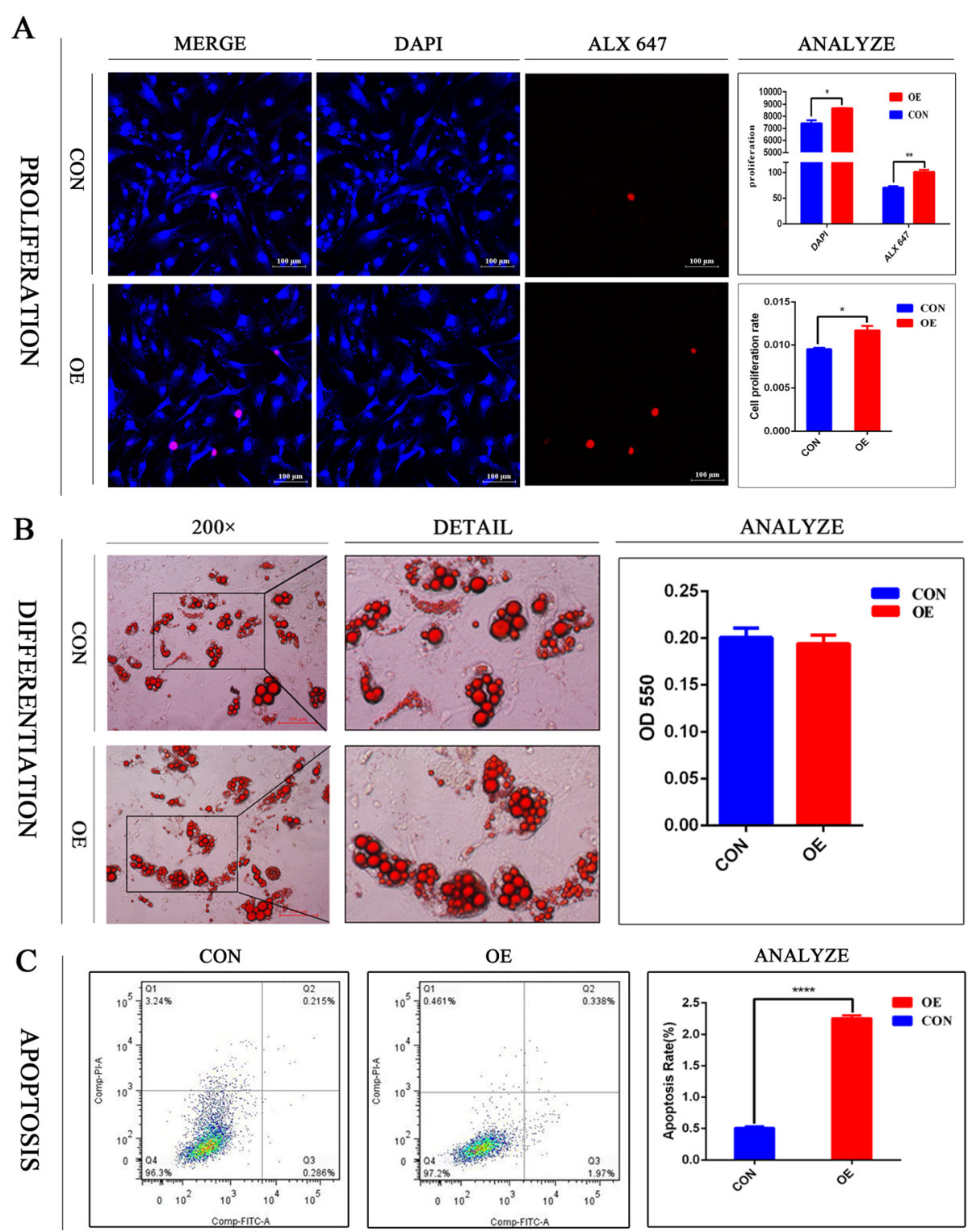

Fig. 3 Effect of Dlgap1 overexpression on BAT cell physiology. a Proliferation of Dlgap1-overexpressing and control brown adipocytes was detected with EdU assays. Red, EdU staining; blue, cell nuclei stained with Hoechst 33342. b Results of Oil Red-O staining of Dlgap 1overexpressing and control BAT. Scale $=100 \mu \mathrm{m}$. Lipid content was measured at $550 \mathrm{~nm}$ using a microplate reader. $\mathbf{c}$ Flow cytometry analysis of apoptosis among Dlgap1-overexpressing and control brown adipocytes

\section{Knocking out Dlgap1 promotes browning-specific gene expression}

To knock out Dlgap1 using CRISPR/Cas9 technology, we designed four sgRNA pairs and determined their cutting efficiency. We found that sgRNA1, sgRNA2, and sgRNA3 acted on adipocytes, with sgRNA2 exhibiting the highest cutting efficiency (Fig. 4a). We also investigated how different transfection times affected transfection efficiency, and demonstrated that $48 \mathrm{~h}$ post-transfection was optimal (Fig. 4a).

After generating Dlgap1-knockout white adipocytes, our RT-qPCR analysis of fat marker genes showed that
Acc, Asc1, Past1, Leptin, Fasn, and Scd expression decreased, while Cidea, Fabp4, Pgc1a, Ppary, Prdm16, and $U_{c p} 1$ were upregulated (Fig. 4c). Western blots confirmed Dlgap1 downregulation, along with decreases in white-fat marker proteins (ACC, ASC1, PAST1, LEPTIN and FASN) to different degrees and increases in brownfat markers (PGC1 $\alpha$, PRDM16, and UCP1) (Fig. 4d). Consistent with the western blot data, immunofluorescence showed a decrease in LEPTIN expression and increase in UCP1 expression (Fig. 4b). Taken together, these results suggest that Dlgap1 knockout in white adipocytes promotes browning. 


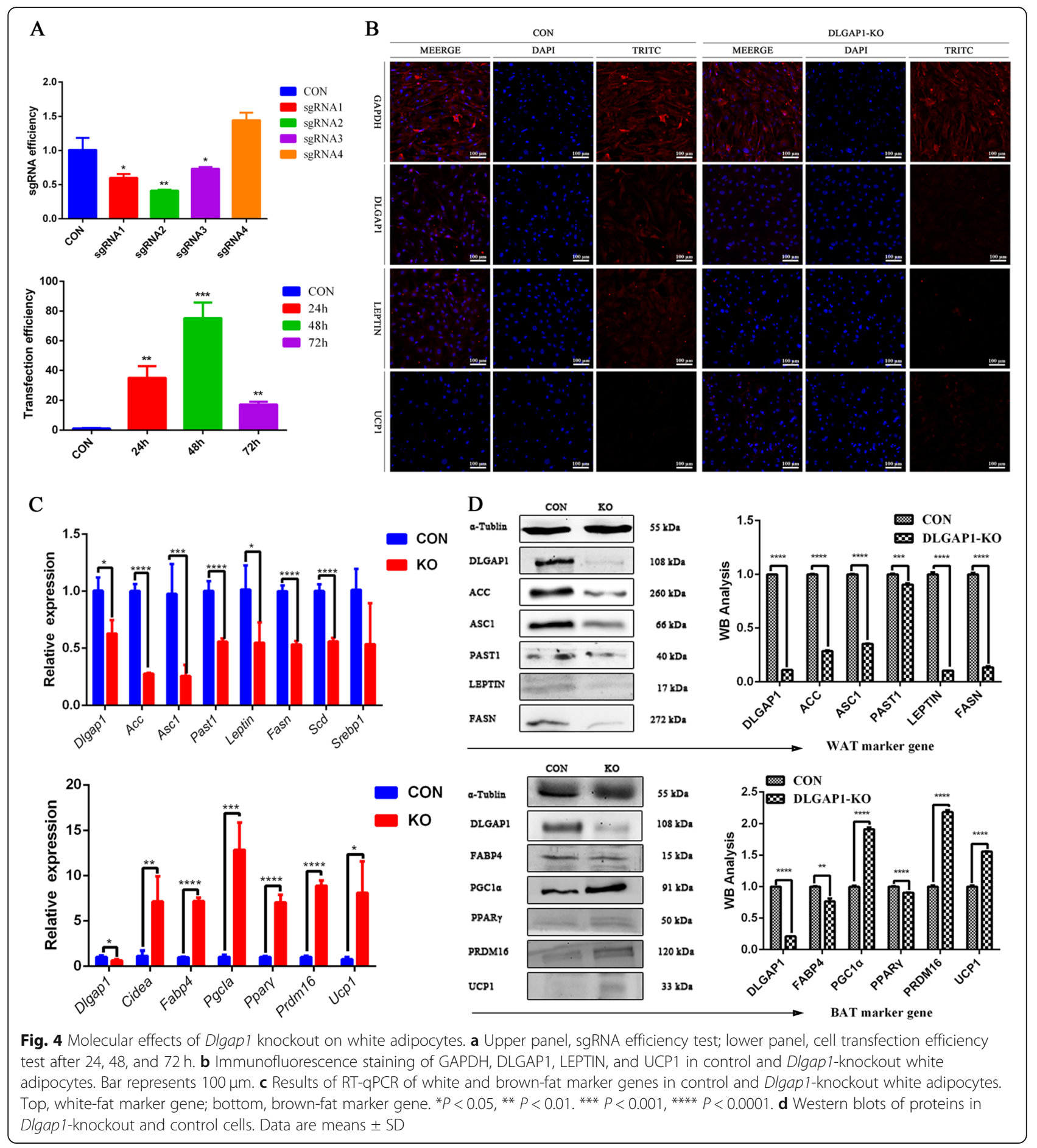

Knocking out Dlgap1 affects white adipocyte formation The results of EdU assays indicated that Dlgap1 knockout in white adipocytes changed proliferation by 0.85 times compared with that of the control group (Fig. 5a). Oil red O staining indicated that Dlgap1 knockout increased adipogenic differentiation (Fig. 5b). Flow cytometry then showed that Dlgap1 knockout slowed adipocyte apoptosis. Furthermore, the knockout group had 0.38 times apoptosis rate as the control group did (Fig. 5c).

\section{Discussion}

White adipose tissue has emerged as a key determinant of healthy metabolism and metabolic dysfunction. This realization is paralleled by the finding that adult humans have heat-dissipating BAT, an important contributor to 

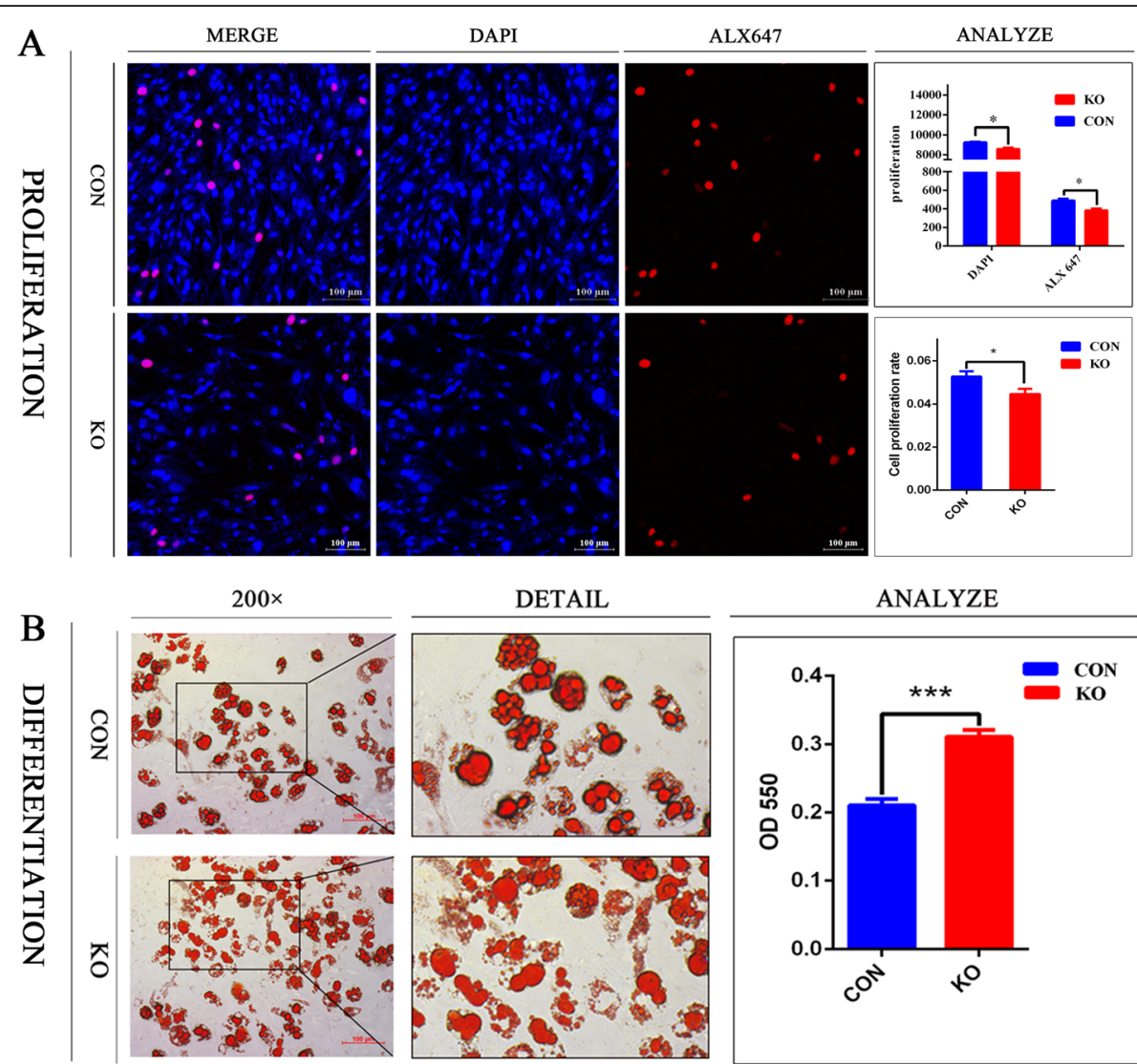

DETAIL
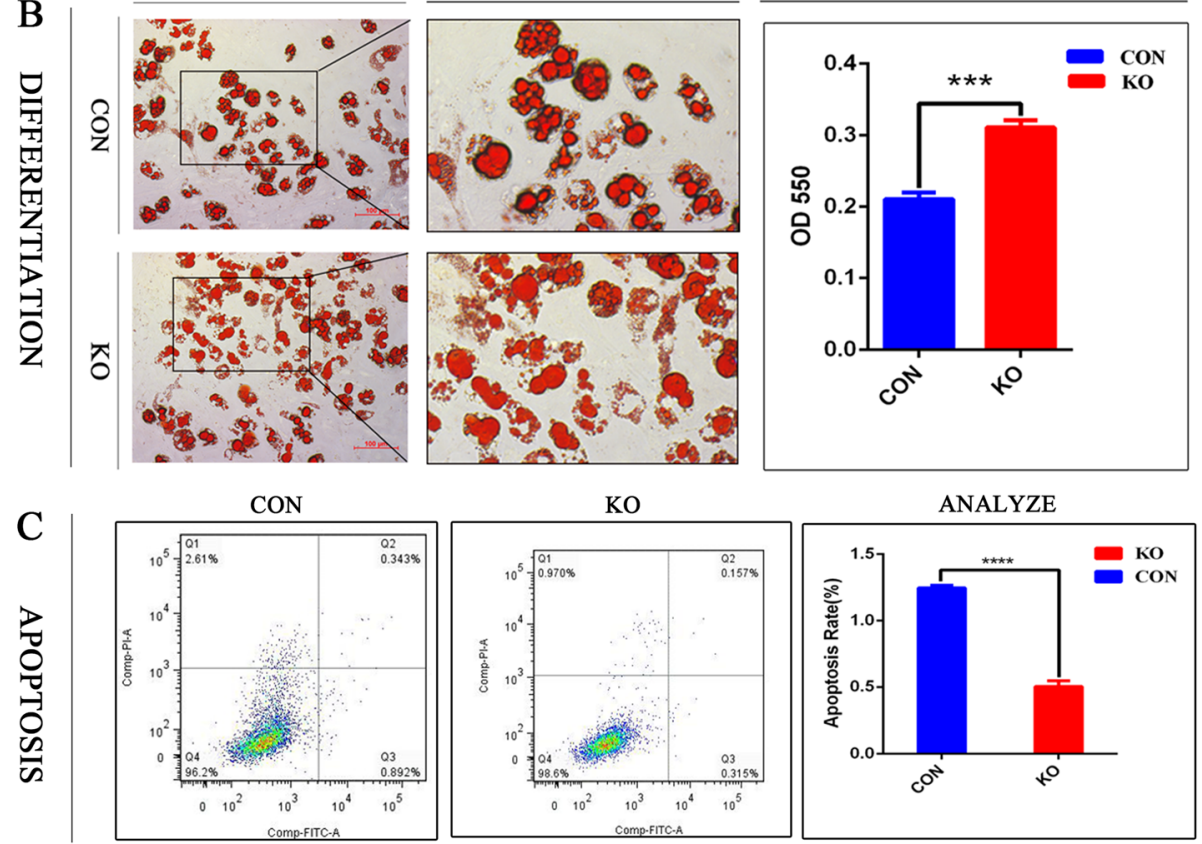

Fig. 5 Effects of Dlgap 1 knockout on the cell physiology of white adipocytes. a Proliferation of Dlgap 1-knockout and control cells was detected by EdU. Red, EdU staining; blue, cell nuclei stained with Hoechst 33342. b Oil Red-O staining of Dlgap 1-knockout and control cells. Scale = 100 mm. Lipid content was measured at $550 \mathrm{~nm}$ using a microplate reader. c Flow cytometry analysis of apoptosis among Dlgap 1-knockout and control cells

energy balance and a possible therapeutic target for treating metabolic disease [34]. We propose that successful targeting of brown and white adipose tissues will depend on research that elucidates their developmental cell-type-specific functional regulators. Here, we explored the effect of Dlgap1 on white fat browning and revealed that Dlgap1 is a negative regulator of this process by influencing cell proliferation and apoptosis.

Genetic Dlgap1 variants are associated with neuropsychiatric disorders, including schizophrenia [35], autism spectrum disorder [36], and obsessive-compulsive disorder [37]. However, the mechanism of Dlgap1 in the browning of white fat remains poorly understood.
Certain Dlgap1 genetic variants are underrepresented in patients with type 2 diabetes in the Netherlands and Korea [28, 38]. Because both obesity and type 2 diabetes are characterized by imbalances in energy metabolism in the human body, Dlgap1 may play an unidentified common role in both conditions. Additionally, Dlgap1 functional variants or genetic variants of neighboring genes that have strong linkage disequilibrium with Dlgap1 could be responsible for both browning and type 2 diabetes.

At the molecular level, we detected the effect of the Dlgap1 gene on white and brown fat marker genes by RT-qPCR, western blots, and immunofluorescence, and 
the results of the three methods were consistent with each other. The Dlgap1 gene was significantly differentially expressed in white and brown fat cells. Knockout of Dlgap1 increased BAT-specific gene expression, while overexpression of Dlgap1 reduced BAT-specific gene expression, especially the expression of UCP1. UCP1 protein plays a key role in the mitochondria in brown fat cells to increase heat production. Viral delivery of irisin, which caused only a moderate increase ( $\sim 3$-fold) in circulating levels, was shown previously to stimulate a 10-20-fold increase in UCP1 levels, increase energy expenditure, and improve glucose tolerance in high-fat fed mice [39].

At the cell level, we examined the effects of Dlgap1 on adipocyte proliferation, differentiation, and apoptosis. We found that Dlgap1 knockout inhibits white adipocyte proliferation, while its overexpression increases dipocyte proliferation. Relevant studies have shown that PPAR $\gamma$ is highly expressed in adipose tissue and is a key factor regulating adipocyte proliferation, differentiation, and increased insulin sensitivity [40]. The mechanisms underlying these patterns may be that Dlgap1 expression affects PPAR $\gamma$, peroxisome proliferator-activated receptor gamma, which also inhibits cell proliferation. In summary, we successfully constructed the overexpression and knockout vector of the Dlgap1 gene, and verified that Dlgap1 negatively regulates the browning of white fat by affecting cell proliferation and differentiation. This study identifies a new function of the Dlgap1 gene in regulating the browning of white fat, laying a foundation for the alleviation and treatment of obesity.

\section{Conclusions}

1. Dlgap1 overexpression in brown adipocytes inhibits brown-fat-related gene expression and promotes white-fat-related gene expression, while also increasing brown adipocyte proliferation and apoptosis.

2. Knocking out Dlgap1 in white fat cells promotes the expression and inhibition of brown-fat-related and white-fat-related genes, respectively. Additionally, knockout inhibits white fat cell proliferation and apoptosis.

3. Dlgap1 negatively regulates the browning of white adipocytes by influencing cell proliferation and apoptosis.

\section{Supplementary information}

Supplementary information accompanies this paper at https://doi.org/10. 1186/s12944-020-01230-w.

Additional file 1: Table S1. The primers of $q-P C R$.

\section{Abbreviations}

ACC: Acetyl-CoA Carboxylase Alpha; ASC1: Solute Carrier Family 7 Member 10; BAT: Brown Adipose Tissue; CRISPR/Cas9: Clustered Regularly Interspaced
Short Palindromic Repeats Cas9; DLGAP1: Discs, Large (Drosophila) HomologAssociated Protein 1; FABP4: Fatty Acid Binding Protein 4, Adipocyte: FASN: Fatty Acid Synthase; PGC1a: Peroxisome Proliferator-Activated Receptor Gamma Coactivator-1a; PPARY: Peroxisome Proliferator-Activated Receptor Gamma; PRDM16: Pr Domain Containing 16; PSAT1: Phosphoserine Aminotransferase 1; SCD: Stearoyl-Coa Desaturase (Delta-9-Desaturase); UCP1: Uncoupling Protein 1

\section{Acknowledgements}

This work was supported by The Science and Technology Innovation Guided Project in Inner Mongolia Autonomous Region (KCBJ2018003).

\section{Authors' contributions}

Conceived and designed the experiments: Ju Zhang. Performed the experiments: Jie Yang, Nan Yang. Analyzed the data: Datong Lu, Jianfei Ma, Yanhua Dong. Reviewed the manuscript: Dongjun Liu, Hao Liang, Ming Cang. Wrote the paper: Ju Zhang. The author(s) read and approved the final manuscript.

\section{Funding}

The Science and Technology Innovation Guided Project in Inner Mongolia Autonomous Region (KCBJ2018003).

\section{Availability of data and materials}

The datasets used and/or analyzed during the current study are available from the corresponding author on reasonable request.

\section{Ethics approval and consent to participate}

C57BL/6 mice were provided by the Experimental Animal Center, Inner Mongolia University. All experiments performed followed the National Research Council Guide for the Care and Use of Laboratory Animals. All protocols were approved by the Institutional Animal Care and Use Committee of Inner Mongolia University.

\section{Consent for publication}

Not applicable.

\section{Competing interests}

The authors declare that they have no competing interests.

Received: 14 November 2019 Accepted: 9 March 2020

Published online: 13 March 2020

References

1. Lloydjones D, Adams R, Carnethon M, Simone GD, Ferguson TB, Flegal K, et al. Heart disease and stroke Statisticsé $¥ 9$ update a report from the American Heart Association statistics committee and stroke statistics subcommittee. Circulation. 2009;119(3):e21-e181.

2. Mann Jl. Diet and risk of coronary heart disease and type 2 diabetes. Lancet. 2002;360(9335):783-9.

3. Lee $\mathrm{DH}$, Hong JE, Yun HM, Hwang CJ, Park JH, Han SB, et al. Interleukin-32 $\hat{I}^{2}$ ameliorates metabolic disorder and liver damage in mice fed high-fat diet. Obesity. 2015;23(3):615-22.

4. Virtanen $\mathrm{K}$, Lidell $\mathrm{M}$, Orava J, Heglind $\mathrm{M}$, Westergren R, Niemi T, Taittonen M, et al. Functional brown adipose tissue in healthy adults. N Engl J Med. 2009; 360(15):1518-25.

5. Natasa P, Walden TB, Shabalina IG, Timmons JA, Barbara C, Jan N. Chronic peroxisome proliferator-activated receptor gamma (PPARgamma) activation of epididymally derived white adipocyte cultures reveals a population of thermogenically competent, UCP1-containing adipocytes molecularly distinct from classic brown adipocyte. J Biol Chem. 2010;285(10):7153.

6. Ishibashi J, Seale P. Medicine. Beige can be slimming. Science. 2010; 328(5982):1113-4.

7. Giralt M, Villarroya F. White, brown, beige/brite: different adipose cells for different functions? Endocrinology. 2013;154(9):2992-3000.

8. Ghorbani M, Himmshagen J. Appearance of brown adipocytes in white adipose tissue during CL 316,243-induced reversal of obesity and diabetes in Zucker fa/fa rats. Int J Obes Relat Metab Disord. 1997;21(6):465-75.

9. Guerra C, Koza RA, Yamashita H, Walsh K, Kozak LP. Emergence of brown adipocytes in white fat in mice is under genetic control. Effects on body weight and adiposity. J Clin Investig. 1998;102(2):412-20. 
10. Xue B, Coulter A, Rim JS, Koza R, Kozak L. Transcriptional synergy and the regulation of Ucp1 during brown adipocyte induction in white fat depots. Mol Cell Biol. 2005;25(18):8311-22.

11. Jeremic N, Chaturvedi P, Tyagi SC. Browning of white fat: novel insight into factors, mechanisms, and therapeutics. J Cell Physiol. 2017;232(1):61-8.

12. Montanari T, Pošćić N, Colitti M. Factors involved in whiteâ toâ brown adipose tissue conversion and in thermogenesis: a review. Obes Rev. 2017; 18(5):495-513.

13. Bond LM, Ntambi JM. UCP1 deficiency increases adipose tissue monounsaturated fatty acid synthesis and trafficking to the liver. J Lipid Res. 2017;59(2):M078469.

14. Werner CM, Schirmer SH, Gensch C, Pavlickova V, Pöss J, Wright MB, et al. The dual PPARI $\pm /^{3}$ agonist aleglitazar increases the number and function of endothelial progenitor cells: Implications for vascular function and atherogenesis. Br J Pharmacol. 2014;171(10):2685-703.

15. Rajakumari S, Wu J, Ishibashi J, Lim HW, Giang AH, Won KJ, et al. EBF2 determines and maintains Brown adipocyte identity. Cell Metab. 2013;17(4): 562-74

16. Villanueva C, Vergnes L, Wang J, Drew B, Hong C, Tu Y, et al. Adipose subtype-selective recruitment of TLE3 or Prdm16 by PPARI ${ }^{3}$ specifies lipid storage versus Thermogenic gene programs. Cell Metab. 2013:17(3):423-35.

17. Erickson HP. Irisin and FNDC5 in retrospect. Adipocyte. 2013;2(4):289-93.

18. Fisher FM, Sandra K, Nicholas D, Fox EC, Mepani RJ, Francisco V, et al. FGF21 regulates $P G C-1 \hat{I} \pm$ and browning of white adipose tissues in adaptive thermogenesis. Genes Dev. 2012;26(3):271-81.

19. Shu-Wen Q, Yan T, Xi L, Yuan L, You-You Z, Hai-Yan H, et al. BMP4-mediated brown fat-like changes in white adipose tissue alter glucose and energy homeostasis. Pnas. 2013;110(9):E798-807.

20. Goody D, Pfeifer A. MicroRNAs in brown and beige fat. Biochim Biophys Acta Mol Cell Biol Lipids. 2019;1864(1):29-36.

21. Mirko T, Kashan A, Esau CC, Markus S. MyomiR-133 regulates brown fat differentiation through Prdm16. Nat Cell Biol. 2012;14(12):1330-5.

22. Yong C, Franziska S, Stefanie K, Bodo H, Holger FH, Gunter M, et al. miR-155 regulates differentiation of brown and beige adipocytes via a bistable circuit. Nat Commun. 2014;4(2):1769.

23. Isabelle G, Bommer GT, Mccoin CS, Sousa KM, Venkatesh K, Macdougald OA Roles for miRNA-378/378* in adipocyte gene expression and lipogenesis. Am J Physiol Endocrinol Metab. 2010;299(2):198-206.

24. Loft A, Forss I, Siersbæk MS, Schmidt SF, Larsen AS, JGS M, et al. Browning of human adipocytes requires KLF11 and reprogramming of PPAR $\hat{i}^{3}$ superenhancers. Genes Dev. 2015;29(1):7.

25. Takeuchi M. SAPAPS. A family of PSD-95/SAP90-associated proteins localized at postsynaptic density. J Biol Chem. 1997;272(18):11943-51.

26. Satoh K, Yanai H, Senda T, Kohu K, Nakamura T, Okumura N, Matsumine A, Kobayashi S, Toyoshima K, Akiyama T. DAP-1, a novel protein that interacts with the guanylate kinase-like domains of hDLG and PSD-95. Genes Cells. 2010;2(6):10

27. Kim E. GKAP, a Novel Synaptic Protein That Interacts with the Guanylate Kinase-like Domain of the PSD-95/SAP90 Family of Channel Clustering Molecules. J Cell Biol. 1997;136(3):669-78.

28. Aulchenko YS, Pullen J, Kloosterman WP, Yazdanpanah M, Hofman A, Vaessen N, et al. LPIN2 Is Associated With Type 2 Diabetes, Glucose Metabolism, and Body Composition. Diabetes. 2007:56(12):3020-6.

29. Kawashima N, Takamiya K, Sun J, Kitabatake A, Sobue K. Differential expression of isoforms of PSD-95 binding protein (GKAP/SAPAP1) during rat brain development. FEBS Lett. 1998;418(3):301-4.

30. Naisbitt S, Valtschanoff J, Allison DW, Sala C, Sheng M. Interaction of the postsynaptic Density-95/Guanylate kinase domain-associated protein complex with a light chain of myosin-V and dynein. J Neurosci. 2000;20(12): 4524-34.

31. Shan T, Liu W, Kuang S. Fatty acid binding protein 4 expression marks a population of adipocyte progenitors in white and brown adipose tissues. FASEB J. 2013;27(1):277-87.

32. Ussar S, Lee KY, Dankel SN, Boucher J, Haering MF, Kleinridders A, et al. ASC1, PAT2, and P2RX5 are cell surface markers for white, beige, and brown adipocytes. Sci Transl Med. 2014;6(247):247ra103.

33. Seale P, Kajimura S, Yang W, Chin S, Rohas LM, Uldry M, et al. Transcriptional control of brown fat determination by PRDM16. Cell Metab. 2007:6(1):38-54

34. Patrick S, Conroe HM, Jennifer E, Shingo K, Andrea F, Jeff I, et al. Prdm16 determines the thermogenic program of subcutaneous white adipose tissue in mice. J Clin Investig. 2011;121(1):96.
35. Föcking M, Lopez LM, English JA, Dicker P, Wolff A, Brindley E, et al. Proteomic and genomic evidence implicates the postsynaptic density in schizophrenia. Mol Psychiatry. 2015;20(4):424-32.

36. Jingjing L, Minyi S, Zhihai M, Shuchun Z, Ghia E, Jennifer Z, et al. Integrated systems analysis reveals a molecular network underlying autism spectrum disorders. Mol Syst Biol. 2014;10(12):774.

37. Ting JT, Peça J, Feng G. Functional consequences of mutations in postsynaptic scaffolding proteins and relevance to psychiatric disorders. Annu Rev Neurosci. 2012;35(35):49.

38. Joon Seol B, Hyun Sub C, Ji-Hong K, Byung Lae P, Jeong-Hyun K, Tae Joon $P$, et al. The genetic effect of copy number variations on the risk of type 2 diabetes in a Korean population. PLoS One. 2011;6(4):e19091.

39. Bostrom P, Wu J, Jedrychowski MP, Korde A, Ye L, Lo JC, et al. A PGC1alpha-dependent myokine that drives brown-fat-like development of white fat and thermogenesis. Nature. 2012;481(7382):463-8.

40. Qiang L, Wang L, Kon N, Zhao W, Lee S, Zhang Y, et al. Brown Remodeling of White Adipose Tissue by SirT1-Dependent Deacetylation of Pparl $\hat{I}^{3}$. Cell. 2012;150(3):620-32.

\section{Publisher's Note}

Springer Nature remains neutral with regard to jurisdictional claims in published maps and institutional affiliations.
Ready to submit your research? Choose BMC and benefit from:

- fast, convenient online submission

- thorough peer review by experienced researchers in your field

- rapid publication on acceptance

- support for research data, including large and complex data types

- gold Open Access which fosters wider collaboration and increased citations

- maximum visibility for your research: over $100 \mathrm{M}$ website views per year

At BMC, research is always in progress.

Learn more biomedcentral.com/submissions 